\title{
EFFECT OF VARIABLE RATE SEEDING ON WINTER WHEAT SEEDBED AND GERMINATION PARAMETERS USING SOIL APPARENT ELECTRICAL CONDUCTIVITY
}

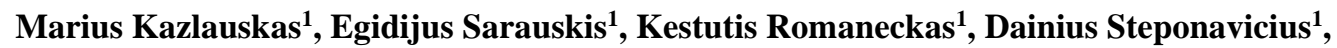 \\ Algirdas Jasinskas ${ }^{1}$, Vilma Naujokiene ${ }^{1}$, Indre Bruciene ${ }^{1}$, Tadas Ziogas ${ }^{1}$, Dovydas Vaicekauskas ${ }^{1}$, \\ Justinas Anusauskas ${ }^{1}$, Abdul Mounem Mouazen ${ }^{2}$ \\ ${ }^{1}$ Vytautas Magnus University, Lithuania; ${ }^{2}$ Ghent University, Belgium \\ marius.kazlauskas@vdu.lt, egidijus.sarauskis@asu.lt, kestas.romaneckas@asu.lt, \\ dainius.steponavicius@asu.lt, algirdas.jasinskas@vdu.lt, vilma.naujokiene@vdu.lt, \\ indre.bruciene@vdu.lt,,tadas.ziogas@stud.vdu.lt, dovydas.vaicekauskas@stud.vdu.lt, \\ justinas.anusauskas@vdu.lt
}

\begin{abstract}
Due to the variability of soil characteristics in the field and the rising prices of high-quality seeds, farmers are increasingly interested in applying a system of precision variable rate seeding (VRS), which makes it easier to manage risks in crop production and allows to ensure the profitability of the farm. Most modern seed drills are equipped with a hydraulic or electric drive and a terminal in the tractor cabin, allowing farmers to apply VRS. The aim of this study was to determine the most appropriate seeding rate of winter wheat according to the measured apparent soil electrical conductivity (ECa) in the field, to investigate the uniformity of seed placement by layers in the soil and to evaluate the germination dynamics of winter wheat. Precision seeding was performed using a VRS map, generated from soil ECa data obtained by field surface scanning using the ECa device EM-38 MK2. Winter wheat seeding was implemented with a direct seed drill. The research was carried out by measuring the parameters of winter wheat seedbed and germinated plants, including the number and distribution of seeds in soil layers of different depths, germination, tillering. Field research was performed with 3 treatments and 4 repetitions ( 1 - uniform rate seeding; 2 - VRS; 3 - VRS + variable rate fertilisation (VRF)). The results of the research showed a direct relationship between the soil ECa and the depth of seed placement. Most seeds were inserted at medium depths $(15-30 \mathrm{~mm})$, except in the soil management zone, where ECa was highest $\left(28.8 \mathrm{mS} \cdot \mathrm{m}^{-1}\right)$. In this area, most seeds $(50.7 \%)$ were inserted shallowly up to $15 \mathrm{~mm}$. The experimental results of seeding studies showed that using the VRS and VRS + VRF methods in all soil zones the germination of winter wheat was similar, while seeding at the uniform rate yielded significant differences between individual soil zones.
\end{abstract}

Keywords: precision seeding, apparent electrical conductivity, soil management zone, seed depth, tillering coefficient.

\section{Introduction}

The pioneers of precision agriculture in variable rate seeding (VRS) became more interested in the mid-1990s [1]. Due to different soil properties in fields, seed germination, crop development, and yield potential may vary [2]. VRS can be the right clue to the required amount of seed accurately inserted into site-specific areas to increase crop yield and profit. One of the most important steps in implementing VRS is to identify the key factors, which have the greatest impact on the yield at each site-specific location, forming separate seeding zones and assigning different seeding rates to them, therefore obtaining a VRS map [1-2]. To optimize the yield when seeding wheat, it is very important to choose the optimal number of plants per unit area. If the plant population is too large, the crop is too dense. It creates additional difficulties in controlling the crop growth during vegetation, as too dense crop can lodge and increase the risk for spread of diseases, which, in turn, requires higher costs to control the disease later. Otherwise, when the number of plants per unit area is too small, it will not be possible to optimize the yields due to plant shortages, which also leads to potential stronger pest exposure to crops and poorer ability to compete with vigour weeds [3]. The relationship between the wheat grain yield and plant density is not consistent, and the mechanisms which can provide answers are not always clear. A better understanding of the relationship between the yield and crop density determinants could lead to improvements in plant density recommendations considering specific soil and environmental characteristics [4]. The recommended increase or decrease in the seed rate in comparison to the average seeding rate depends on the productivity potential of the respective soil management area [5]. One of the important physical soil properties is the apparent electrical conductivity (ECa) of the soil, capability of transmitting electric current [3; 6]. Soil ECa measurements correlate with physical and chemical soil properties, including the soil structure, drainage conditions, salinity, and subsoil properties that affect crop productivity [2; 7]. Griffin et al. [3] have made assessments of the soil texture, soil depth to subsoil, 
colour, stone content, and landscape position beside ECa. They found that it is worth to use VRS when differences between zones is over $12 \%$.

The agrotechnological processes of variable wheat seeding of winter wheat in the conditions of the Baltic region were studied for the first time. This is a new research to achieve greater profitability. The aim of the study was to determine and compare the influence of different seeding methods on seed insertion, germination, and tillering parameters.

\section{Materials and methods}

Experimental field research was carried out in the northern part of Lithuania (coordinates: $55^{\circ} 40^{\prime}$

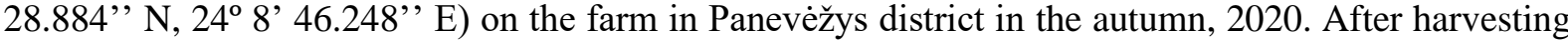
peas, winter wheat (Triticum aestivum L.) variety "Skagen" was seeded using different seeding methods. According to the international classification, the experimental field soil was described as sandy to silty loam [8]. The studies were performed with 3 treatments and 4 repetitions: the first involves control, seeding and fertilization at the uniform rate (hereinafter URS); the second is seeding at a variable rate (VRS) and fertilization at a uniform rate; the third - variable seeding and fertilization (VRS + VRF). Total field width was $450 \mathrm{~m}$, length $-600 \mathrm{~m}$. The width of each plot was $36 \mathrm{~m}$.

In the region where the experimental field studies were carried out, during the period of seed germination, tillering the average monthly rainfall from the $16^{\text {th }}$ of September to the $20^{\text {th }}$ of November 2020 was about $46.2 \mathrm{~mm}$, and the total rainfall during the whole period was $99.3 \mathrm{~mm}$. The highest precipitation fell on the $14^{\text {th }}$ of October $(15.1 \mathrm{~mm})$. The average monthly weather temperature was about $10.4^{\circ} \mathrm{C}$. The highest temperature during the study period was set on the $26^{\text {th }}$ of September $\left(20.0^{\circ} \mathrm{C}\right)$ and the lowest on the $10^{\text {th }}$ of November $\left(2.4^{\circ} \mathrm{C}\right)$.

On the $11^{\text {th }}$ of August 2020, the boundaries of the study field were measured with off-road vehicle Toyota Hilux (Toyota Motor Corporation, Toyota, Japan), using GPS coordinate positioning equipment Trimble EZ-Guide 250 with GPS antenna (Trimble Navigation Ltd, Alpharetta, USA), and determined the total field area of $22.37 \mathrm{ha}$. To determine differences of soil properties in the field and to create an accurate soil sampling plan and variable seeding rate map, soil was scanned using an EM38-MK2 electrical conductivity scanner (Geonics Ltd) prior to the experimental field studies. Measurements of soil electrical conductivity $\left(\mathrm{mS} \cdot \mathrm{m}^{-1}\right)$ from 0 to $1.5 \mathrm{~m}$ depth were performed at a speed of $10-15 \mathrm{~km} \cdot \mathrm{h}^{-1}$ driving on technological tracks every $24 \mathrm{~m}$ by towing the device EM38-MK2 mounted on plastic sleds (Fig. 1). The non-contact instrument includes two receiver coils, each orientated with vertical dipoles, separated by $1 \mathrm{~m}$ and $0.5 \mathrm{~m}$ from the transmitter, offering two effective depth ranges $0.7 \mathrm{~m}$ in vertical and $1.5 \mathrm{~m}$ in horizontal mode. So, it is possible to operate the instrument by changing the effective depth ranges. The transmitting coil sending an electrical field into the soil and the capacity to hold the electrical field is closely related to the soil properties [7].

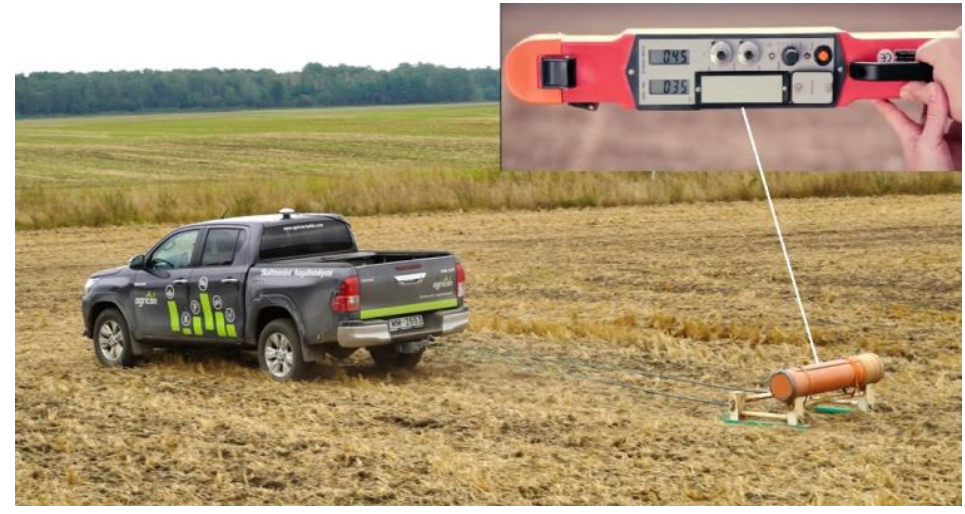

Fig. 1. Determination of soil electrical conductivity (ECa) with EM38-MK2 scanner

Using the Open Source Geographic Information System (QGIS) program, considering similar sitespecific soil properties, 7 plots were created, with an average area of 3 ha each. Soil samples were taken using semi-automatic soil sampling equipment (Fig. 2) manufactured by Agricon (Germany) and Adigo AS (Norway), representative soil samples were taken on the $12^{\text {th }}$ of August 2020 and various soil 
properties, such as soil texture, $\mathrm{pH}, \mathrm{P}$ (phosphorus), $\mathrm{K}$ (potassium), $\mathrm{Mg}$ (magnesium) and organic matter content were determined.

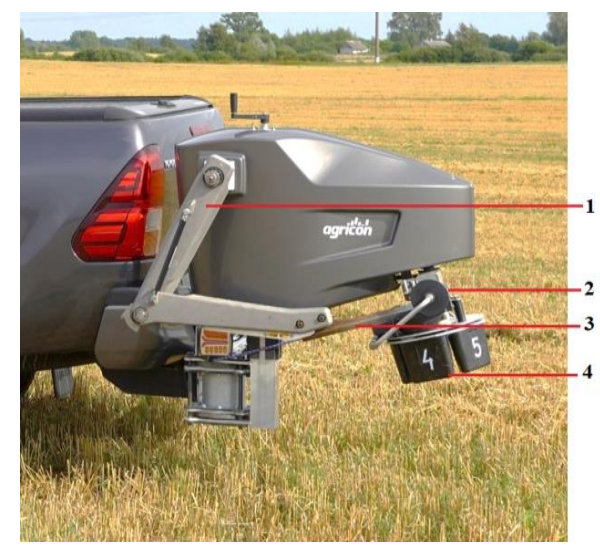

Fig. 2. Semi-automatic soil sampling equipment: 1 - automatically operated mechanical hand; 2 - needle cleaning mechanism; 3 - needle for taking soil samples from a depth of $20-30 \mathrm{~cm} ; 4$ - soil sample collection boxes

Up to 20 soil sub-samples were automatically taken from each plot along the $\mathrm{Z}$ trajectory. The subsamples formed one united sample. A total of 7 aggregate soil samples of 300-500 g each with different soil structures were formed from different plots. The $\mathrm{pH}$ and $\mathrm{Mg}\left(\mathrm{CaCl}_{2}\right.$ method), $\mathrm{K}$ and $\mathrm{P}$ (CAL method), as well as the organic matter and granulometric composition of the soil samples were performed at an accredited laboratory of Agrolab GmbH (Leinefelde-Worbis, Germany).

According to the differences in the soil apparent electrical conductivity, the field was divided into 5 soil management zones (MZ) and a VRS map was created using QGIS software. In the MZ with the highest ECa the lowest seeding rate was set. The higher ECa related to better water supply capacity for the plants in the heavier soil, and tillering potential could be higher to compensate smaller plant density. In MZ with the lowest ECa was set the highest seeding rate since in sandy soil plants can reduce tillers, so the loss of the tillers should be compensated with higher plant density. When creating VRS maps, only the ECa parameter was taken as a basis, since ECa the best represents variability of the soil properties in the entire field. Soil ECa is achieved, firstly by salts contained in water present in large pores; consequently, the measurement of ECa in the mass of the soil is closely related to its salinity [7]. There is also a contribution of the solid phase of the wet soil to ECa, by the exchange of associated cations of clay minerals [7]. The third way of conductivity is consisting of soil particles in permanent contact with each another. These three paths of current flow contribute to the ECa of the soil. On the $16^{\text {th }}$ of September 2020 winter wheat was sown. The seeding was based on theVRS map. The Horsch Avatar 6.16 SD direct seed drill (HORSCH Industrietechnik GmbH, Germany) was used for seeding in a uniform $\left(180 \mathrm{~kg} \cdot \mathrm{ha}^{-1}\right)$ and variable rate from 146 to $214 \mathrm{~kg} \cdot \mathrm{ha}^{-1}$, seeding at $167 \mathrm{~mm}$ width row spacing, $30 \mathrm{~mm}$ depth, $10 \mathrm{~km} \cdot \mathrm{h}^{-1}$ speed.

On the same day after seeding the Kritz/Häkansson seedbed test method [9] determined the seed distribution by depth, estimating the percentage of seeds inserted in the upper 0-15 mm, middle 15$30 \mathrm{~mm}$, and deeper than $30 \mathrm{~mm}$. layer. One month after seeding, the germinated plants were counted. Two months after seeding plants from different rows of $0.50 \mathrm{~m}$ were dug in different $\mathrm{MZ}$ and the number of stems from each plant were counted to determine the plant tillering coefficient.

To ensure statistical reliability of the results, experimental field studies of 3 different variants were performed in 4 repetitions. In each repetition seed distribution by depth, germination, and tillering were measured 5 times, for a total of 60 times. Data from experimental studies were processed using one-way analysis with program ANOVA. Data were evaluated by calculating the smallest significance difference $(p<0.05)$ using Student T-test. In Figures 4 and 5, the same letters mean that there was no significant difference between the different MZs.

\section{Results and discussion}

After analyzing the experimental field soil properties results, it was found that the average $\mathrm{pH}$ of the whole field soil was 7.3 (ranged from 6.6 to 7.5), the average phosphorus (P) content was $4.2 \mathrm{mg}$ 
per $100 \mathrm{~g}^{-1}\left(3.1-5.5 \mathrm{mg}\right.$ per $\left.100 \mathrm{~g}^{-1}\right)$, potassium $(\mathrm{K}) 12.1 \mathrm{mg} \cdot 100 \mathrm{~g}^{-1}\left(10.4-13.9 \mathrm{mg} \cdot 100 \mathrm{~g} \mathrm{~g}^{-1}\right)$, magnesium $(\mathrm{Mg})-14.9 \mathrm{mg} \cdot 100 \mathrm{~g}^{-1}\left(12.1-16.7 \mathrm{mg} \cdot 100 \mathrm{~g} \mathrm{~g}^{-1}\right)$, organic matter $-2.0 \%(1.6-2.7 \%)$. The distribution of the above-mentioned main soil elements in the field was even and ranged from 80 to $87 \%$ within one class.

After soil scanning in the field an ECa map was prepared (Fig. 3a), according to which a VRS map for winter wheat was created. If the first treatment (control) for winter wheat seeding uniform seeding rate (URS) of $180 \mathrm{~kg} \cdot \mathrm{ha}^{-1}$ was used, which is typical for this region [10], then in other treatment sites in each soil management zone (MZ) a variable seeding rate, which varied from URS by about $20 \%$, from a minimum of $146 \mathrm{~kg} \cdot \mathrm{ha}^{-1}$ (MZ1) to a maximum of $214 \mathrm{~kg} \cdot \mathrm{ha}^{-1}$ (MZ5) (Fig. 3b).

a)

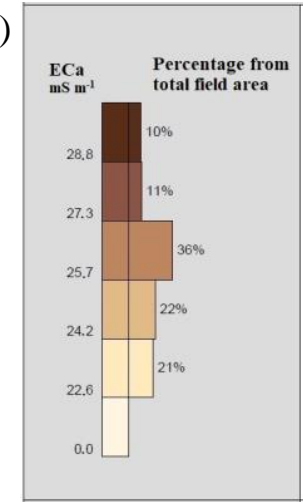

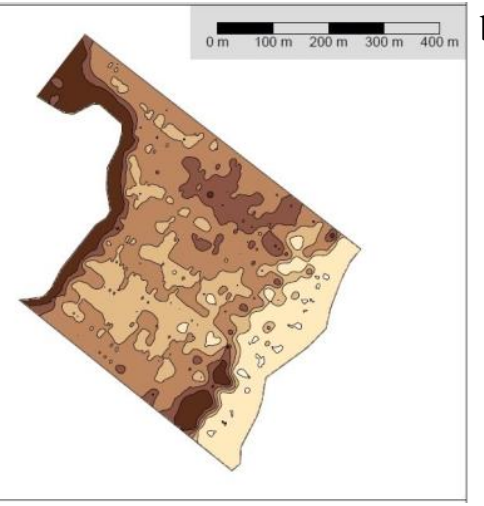

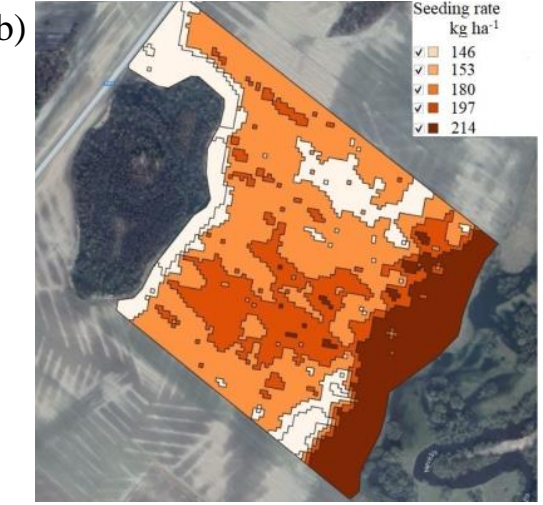

Fig. 3. Maps: $a-$ soil ECa; $b$ - variable rate seeding

On the same day after seeding, the distribution depth of winter wheat seeds in the soil layers was determined in each MZ. The seed distribution data presented in Table 2 show that in the MZ1 zone the majority of seeds $(50.7 \%)$ were deposited in the top 0-15 mm soil layer. In other MZs, most seeds were found at the depths of 15-30 mm. In the MZ1 zone, the shallower seed distribution may have been influenced by heavier and more compacted soils, as this zone was located at the edge of the field - in the headlands. In this soil zone, the ECa was the highest at $28.6 \mathrm{mS} \cdot \mathrm{m}^{-1}$. Assessing the influence of soil, it is known that the optimal seeding depth decreases with increasing the clay content [2].

Table 2

Average seed distribution by depth in different soil management zones

\begin{tabular}{|c|c|c|c|c|c|}
\hline \multirow{2}{*}{$\begin{array}{c}\text { Management } \\
\text { zone }\end{array}$} & \multirow{2}{*}{ ECa, $\mathbf{~ m S} \cdot \mathbf{m}^{-\mathbf{1}}$} & \multirow{2}{*}{${\text { VRS, } \mathbf{~ k g} \cdot \mathbf{h a}^{-1}}^{\mathbf{1}}$} & \multicolumn{3}{|c|}{ Average seed distribution by depth, \% } \\
\cline { 4 - 6 } & 28.6 & 146 & $\mathbf{0 - 1 5} \mathbf{~ m m}$ & $\mathbf{1 5 - 3 0} \mathbf{~ m m}$ & $\mathbf{3 0} \mathbf{~ m m}$ \\
\hline MZ1 & 28.7 & 153 & 24.4 & 39.0 & 10.3 \\
\hline MZ2 & 27.3 & 180 & 35.3 & 4.7 & 23.9 \\
\hline MZ3 & 25.7 & 197 & 25.7 & 50.5 & 15.2 \\
\hline MZ4 & 24.2 & 214 & 24.5 & 53.3 & 23.4 \\
\hline MZ5 & 22.6 & 22.3 \\
\hline
\end{tabular}

The results of winter wheat seed germination studies demonstrate that the physical properties of the soil and the method of seeding can have a significant effect on plant germination. With URS treatment (control), the germination of winter wheat seeds (MZ1 - 62.7\% and MZ2 - 72.6\%) was significantly lower in the two study field areas with the highest soil ECa than in the rest soil management areas. According to Griffin et al. [3], changes in seed germination may have been influenced by the soil structure and seedbed quality. No significant differences were found between the different soil MZs using the variable rate seeding method in the rest treatments. The results of wheat germination obtained by Taylor et al. [11] showed that there was no significant difference in germination between the three different VRS zones, but it was observed that the number of stems increased more in the zone of maximum seeding rate than in other zones.

Analyzing the tillering results of winter wheat (Fig. 5), it was observed that in MZ1 and MZ2 zones, where the soil was heavier, seeding by the URS method resulted in a lower plant tillering coefficient than in other MZs, but no significant difference was found. Using the VRS method, the fluctuations of the wheat tillering coefficient between MZ zones were small, the lowest coefficient was in MZ4 with ECa $24.2 \mathrm{mS} \cdot \mathrm{m}^{-1}$, the seeding rate $-197 \mathrm{~kg} \cdot \mathrm{ha}^{-1}$. The significant difference in the tillering coefficient 
of winter wheat was calculated only in VRS + VRF treatment between the zones MZ4 and MZ5. There are no obvious explanations for this difference yet. Such results may have been influenced by the field topography, field heterogeneity, or higher weediness in the MZ4 zone.

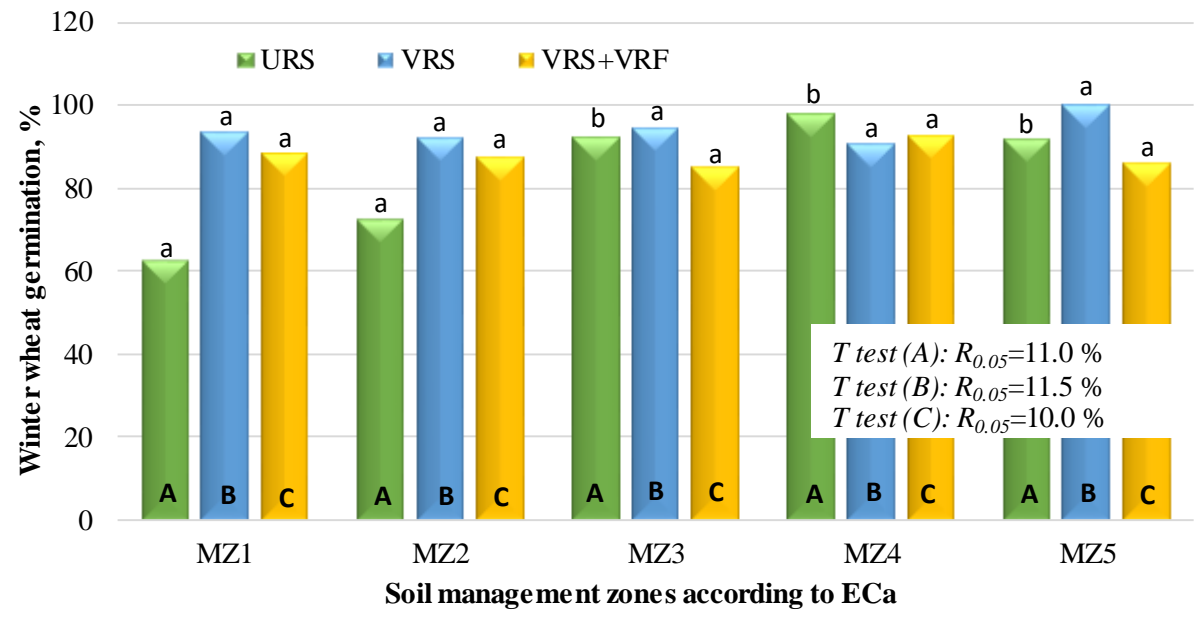

Fig. 4. Effect of precision seeding on winter wheat germination in different soil management zones

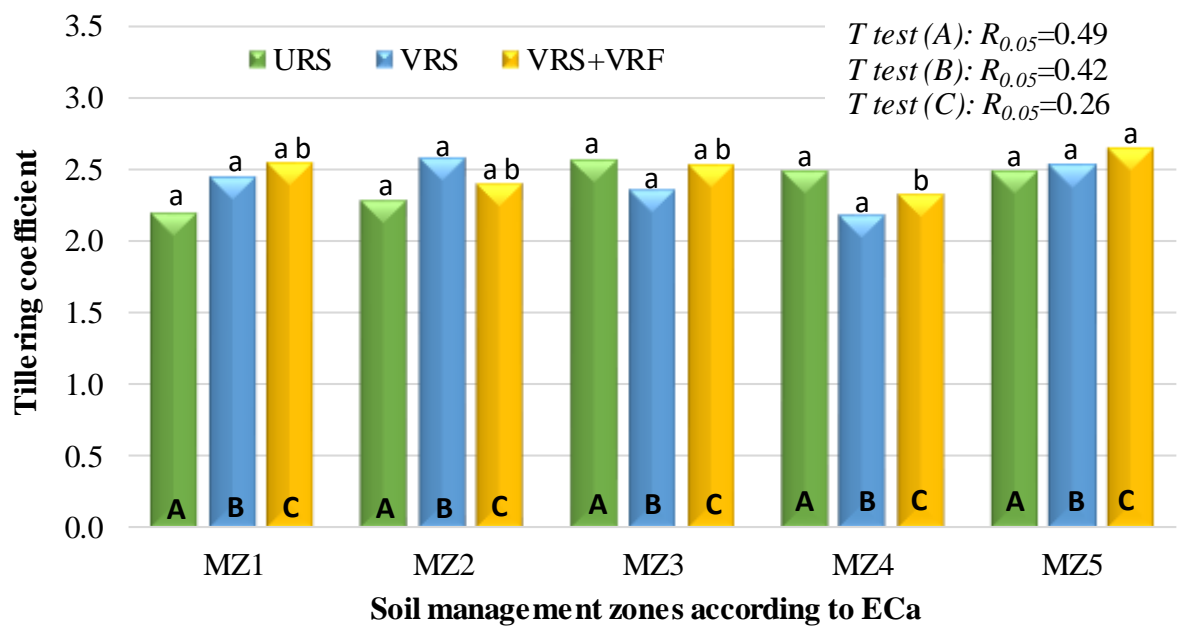

Fig. 5. Effect of precision seeding on winter wheat tillering coefficient in different soil management zones

To sum up the influence of different seeding methods on different winter wheat production indicators, initial assumptions can be made that the unevenness of the field soil can have a significant impact on the quality of seed placement, germination, and plant tillering. The VRS method makes it possible to reduce the effect of different properties of $\mathrm{MZ}$ on the above-mentioned parameters in winter wheat production. Some authors, who have performed similar studies with VRS, reported that the number of wheat stems per unit area was statistically affected by seeding rate. They found that when seeding $175 \mathrm{~kg} \cdot \mathrm{ha}^{-1}$, the rate of stems was 503 , and when seeding $150 \mathrm{~kg} \cdot \mathrm{ha}^{-1}$, statistically less 464 stems [12]. Gaile et al. [10] reported that the seeding rate had no effect on winter wheat formation elements. Some studies have shown that increasing the seeding rate decreases the number of productive stems [13]. This may be due to the fact that when seeding above the optimal rate, the number of stemS.may decrease due to competition between plants [12]. The results of other authors [14] show that long-term application of the variable rate method to crops and a good understanding of field variability can increase the plant productivity, fertilizer efficiency and improve farm management solutions. 


\section{Conclusions}

1. The interactions between the soil electrical conductivity in different management zones (MZ) and the seed placement depth showed that seed placement was the shallowest in heavier soils with the highest soil electrical conductivity (ECa).

2. Based on the results of winter wheat seed germination, it can be assumed that at different seeding rates the seed germination was similar in different soil MZs, but at the uniform seeding rate in the control treatment the germination was significantly lower in the areas with the highest ECa.

3. There were no significant differences in winter wheat tillering coefficients in all seeding treatments between different soil MZs, except for one, when VRS + VRF treatment showed a significant difference between the lightest soil MZ4 $\left(\mathrm{ECa}-24.2 \mathrm{mS} \cdot \mathrm{m}^{-1}\right)$ and MZ5 $\left(22.6 \mathrm{mS} \cdot \mathrm{m}^{-1}\right)$ zones.

\section{Acknowledgements}

This project has received funding from the Research Council of Lithuania (LMTLT), agreement No 01.2.2-LMT-K-718-03-0041.

\section{References}

[1] Fulton J. Variable-rate seeding systems for precision agriculture. In Precision agriculture for sustainability, Stafford J. (Ed.), Burleigh Dodds Science Publishing Limited, 2019, pp. 285-297.

[2] Munnaf M.A., Haesaert G., Van Meirvenne M., Mouazen A.M. Site-specific seeding using multisensor and data fusion techniques: A review. Advances in Agronomy, vol. 161, 2020, pp. 241-323.

[3] Griffin S., Hollis J. Using profile soil electrical conductivity survey data to predict wheat establishment rates in the United Kingdom. Papers presented at the $9^{\text {th }}$ European Conference of Precision Agriculture'13, Lleida, Catalonia, Spain, 2013, pp. 491-497.

[4] Bastos L.M., Carciochi W., Lollato R.P., Jaenisch B.R., Rezende C.R., Schwalbert R., Wright Y. Winter wheat yield response to plant density as a function of yield environment and tillering potential: A review and field studies. Frontiers in Plant Science, vol. 11(54), 2020, pp. 1-17.

[5] Lovell A. Variable-rate seeding next step in precision farming. 2016. [online] [25.02.2021]. Available at: https://www.manitobacooperator.ca/crops/variablerate-seeding-next-step-inprecision-farming/.

[6] Kazlauskas M, Bručienė I, Jasinskas A, Šarauskis E. Comparative analysis of energy and GHG emissions using fixed and variable fertilization rates. Agronomy, vol. 11(1), 138, 2021, pp. 1-19.

[7] Grisso R.B., Alley M., Wysor W.G., Holshouser D., Thomason W. Precision farming tools: Soil electrical conductivity. Virginia Cooperative Extension, 2009, pp. 1-6.

[8] Von Wulffen U., Roschke M., Kape H.E. Guide values for examination and advice as well as for the technical implementation of the Fertilizer Ordinance (DüV). State Office for Consumer Protection, Frankfurt (Oder), 2008, pp. 1-84.

[9] Håkansson I., Myrbeck A., Etana, A. A review of research on seedbed preparation for small grains in Sweden. Soil and Tillage Research, vol. 64(1-2), 2002, pp. 23-40.

[10] Gaile Z., Ruza A., Kreita D., Paura L. Yield components and quality parameters of winter wheat depending on tillering coefficient. Agronomy research, vol. 15(1), 2017, pp. 79-93.

[11] Taylor J., Mason M., Whelan B., McBratney A. Determining optimum management zone-based seeding rates using on-farm experimentation and variable rate seeding technologies. Proceedings of the $8^{\text {th }}$ International Conference on Precision Agriculture. July 23-26, 2006, Minneapolis, USA, CD-ROM.

[12] Iqbal J., Hayat K., Hussain S., Ali A., Bakhsh M.A.A.H.A. Effect of seeding rates and nitrogen levels on yield and yield components of wheat (Triticum aestivum L.). Pakistan Journal of Nutrition, vol. 11(7), 2012, pp. 531-536.

[13] Ayalew T., Abebe B., Yoseph T. Response of wheat (Tritium aestivum L.) to variable seed rates: The Case of Hawassa area, southern Ethiopia. African Journal of Agricultural Research, 12(14), 2017, pp. 1177-1181.

[14] Kayad A., Sozzi, M., Gatto, S., Whelan, B., Sartori, L., Marinello, F. Ten years of corn yield dynamics at field scale under digital agriculture solutions: A case study from North Italy. Computers and Electronics in Agriculture, vol. 185, 106126, 2021, pp. 1-12. 